Jiannan Pei, Junwen Zhou, Feng Jiang, Kaihua Chen, Shaohua Yin*, Libo Zhang, Jinhui Peng and Yaping Lin

\title{
Kinetics analysis of the forward extraction of cerium(III) by D2EHPA from chloride medium in the presence of two complexing agents using a constant interfacial area cell with laminar flow
}

https://doi.org/10.1515/gps-2017-0035

Received May 11, 2017; accepted August 1, 2017; previously published online September 26, 2017

Abstract: The kinetic studies performed on the forward extract of cerium(III) from chloride solution with the complex agents, citric acid ( $\left.\mathrm{H}_{3} \mathrm{Cit}\right)$ and lactic acid (HLac) in the presence of di-(2-ethylhexyl)phosphoric acid (D2EHPA, $\mathrm{H}_{2} \mathrm{~A}_{2}$ ) have been investigated using a constant interfacial area cell with laminar flow. The effects of stirring speed, temperature, and specific interfacial area on the extraction rate are discussed separately, and the results show that the extraction process is a diffusion-controlled kinetics process with an interfacial reaction. Studies on the effect of $\mathrm{pH}$ value and $\mathrm{H}_{2} \mathrm{~A}_{2}$ concentration on the extraction rate are used to obtain the rate equation. The rate-controlling step is also suggested by the predictions derived from the interfacial reaction models, and the rate equation obtained by the kinetic model is consistent with that obtained by the experimental results. The information on the extraction kinetics in this extraction system will provide some knowledge of its application.

\footnotetext{
*Corresponding author: Shaohua Yin, State Key Laboratory of Complex Nonferrous Metal Resources Clean Utilization, Kunming University of Science and Technology, 68 Wenchang Road, Kunming, Yunnan 650093, China; Faculty of Metallurgical and Energy Engineering, Kunming University of Science and Technology, Kunming, Yunnan 650093, China; Key Laboratory of Unconventional Metallurgy, Ministry of Education, Kunming, Yunnan 650093, China; and National Local Joint Laboratory of Engineering Application of Microwave Energy and Equipment Technology, Kunming, Yunnan 650093, China, e-mail: yinsh@kmust.edu.cn Jiannan Pei, Junwen Zhou, Feng Jiang, Kaihua Chen, Libo Zhang and Jinhui Peng: State Key Laboratory of Complex Nonferrous Metal Resources Clean Utilization, Kunming University of Science and Technology, Kunming, Yunnan 650093, China; Faculty of Metallurgical and Energy Engineering, Kunming University of Science and Technology, Kunming, Yunnan 650093, China; Key Laboratory of Unconventional Metallurgy, Ministry of Education, Kunming, Yunnan 650093, China; and National Local Joint Laboratory of Engineering Application of Microwave Energy and Equipment Technology, Kunming, Yunnan 650093, China Yaping Lin: Faculty of Adult Education, Kunming University of Science and Technology, Kunming, Yunnan 650093, China
}

Keywords: cerium(III); complex agents; constant interfacial area cell; D2EHPA extractant; extraction kinetics.

\section{Introduction}

Cerium(III) is a valuable metal in high demand. Out of the entire amount of cerium that is being used worldwide, approximately $90 \%$ is utilized in producing polishing powder [1, 2]. Other ways in which it is used are for glass-fiber, catalysts, ceramics, and many others [3-5]. The most efficient method of its production is through solvent extraction, which plays an important role for the production of cerium and/or cerium compounds within the hydrometallurgy industry [6].

Currently, the researches consider cationic organophosphorous extractants, such as di-2-ethylhexyl phosphoric acid (D2EHPA) and 2-ethylhexyl phosphonic acid mono-(2-ethyl hexyl) ester (HEH/EHP), as the main solvents employed to separate rare earths in the rare earth industries [7-9]. However, these extractants cannot separate or purify rare earths easily, because of the close physical and chemical properties among the rare earths $[10,11]$. That is the reason for a growing interest in the development of newer extractants and also for the extraction systems used in separation of, as a group or from one another. Currently, there is considerable attention on the different complex formation constants, which is effective in the separation of lanthanides [12, 13]. The information on complex extraction in the presence of both the complex agents such as lactic acid and citric acid has been obtained from our previous studies, and the results indicate that the chelating extraction would not only improve the extraction capacity of D2EHPA and/or HEH/EHP, but also heighten its selectivity with some of the adjacent rare earths [14-16]. In fact, information on the kinetics of lanthanides(III) has been studied in many literatures, for example, the extraction kinetics of ytterbium(III), cerium(IV), and neodymium(III) using constant interfacial cell with laminar flan has been investigated by many researchers, and the effects of stirring speed, temperature, and species concentration on the extraction rate are discussed in detail; the rate-controlling step is also proposed 
[17-19]. However, until now, no reports on the extraction kinetics of the complexing extraction system containing two complexing agents namely lactic acid and citric acid with D2EHPA extractant are available.

Therefore, to develop a perfect separation technology, and also to improve the element pairs of selectivity being superior to the currently existing HEH/EHP and/or D2EHPA system, it is essential to obtain the information on the data of extraction kinetics in clarifying extraction mechanism and chemical reaction rate, to explain the extraction process in whole [20, 21]. This work aims to study the extraction rate of Ce(III) from aqueous phase containing two complexing agents lactic acid and citric acid as a function of the stirring speed, temperature and specific interface area, as well as the extractant concentration and aqueous acidity, to obtain the extraction regime and rate equation. In addition, a kinetic model has been elaborated.

\section{Materials and methods}

\subsection{Reagents and apparatus}

D2EHPA $\left(\mathrm{H}_{2} \mathrm{~A}_{2}\right)$ extractant with sulfonated kerosene was brought from Luoyang ZhongDa Chemical Industry Co., Ltd. (China) A certain known amount of D2EHPA is first diluted until it has reached the required concentration having appropriate sulfonated kerosene; for a situation like this, the D2EHPA will have the ability to form a dimer $\mathrm{H}_{2} \mathrm{~A}_{2}$, e.g. $2 \mathrm{HA} \stackrel{K_{\mathrm{d}}}{\rightleftarrows} \mathrm{H}_{2} \mathrm{~A}_{2}$. As the dimerization is constant $\left(K_{\mathrm{d}}\right)$ and is defined as: $K_{\mathrm{d}}=\left[\mathrm{H}_{2} \mathrm{~A}_{2}\right] /[\mathrm{HA}]^{2}, \log K_{\mathrm{d}}=4.42$ [22], its dissociation reaction goes like this: $\mathrm{HA} \stackrel{K_{\mathrm{a}}}{\rightleftarrows} \mathrm{H}^{+}+\mathrm{A}^{-}$, when the dissociation constant $\left(K_{\mathrm{a}}\right)$ will be defined as: $K_{\mathrm{a}}=\left[\mathrm{H}^{+}\right]\left[\mathrm{A}^{-}\right] /[\mathrm{HA}], \mathrm{p} K_{\mathrm{a}}=1.27$, at $T=25^{\circ} \mathrm{C}[22]$.

The stock solution of aqueous phase is prepared by dissolving $\mathrm{CeCl}_{3}$ (Chengdu Aikeda Chemical Reagent Co., Ltd., China) (purity $>99.9 \%$ ) using distilled water, and diluted to the required volume, and then analyzed by titration using a standard solution of EDTA (Tianjin Fengchuan Chemical Reagent Technologies Co., Ltd., China) at pH 5.5 using xylenol orange (Shanghai Xinshengshi Chemical Science Co., Ltd., China) as an indicator. A $1.0 \mathrm{~mol} \mathrm{l}^{-1}$ of $\mathrm{NaCl}$ is used to maintain a constant ionic strength. Lactic acid (HLac, $\mathrm{p} K_{\mathrm{a}}=3.86$, at $\left.T=25^{\circ} \mathrm{C}[23]\right)$ and citric acid $\left(\mathrm{H}_{3} \mathrm{Cit}, \mathrm{p} K_{\mathrm{a} 1}=3.13\right.$, $\mathrm{p} K_{\mathrm{a} 2}=4.76, \mathrm{p} K_{\mathrm{a} 3}=6.40$, at $\left.T=25^{\circ} \mathrm{C}[23]\right)$ are obtained from the Sinopharm Chemical Reagent Co. Ltd (China). All the chemicals are of analytical reagent grade.

A model of pHS-3C digital pH meter (Shanghai Rex Instruments Factory, China) is employed to measure the acidity. The cerium concentrations during extraction process are all determined using the Prodigy high dispersion inductively coupled plasma spectrometer (Leeman Labs, USA).

\subsection{Experimental procedure}

The constant interfacial area cell with laminar flow is used to conduct the kinetic experiment based on the principle found in the literature

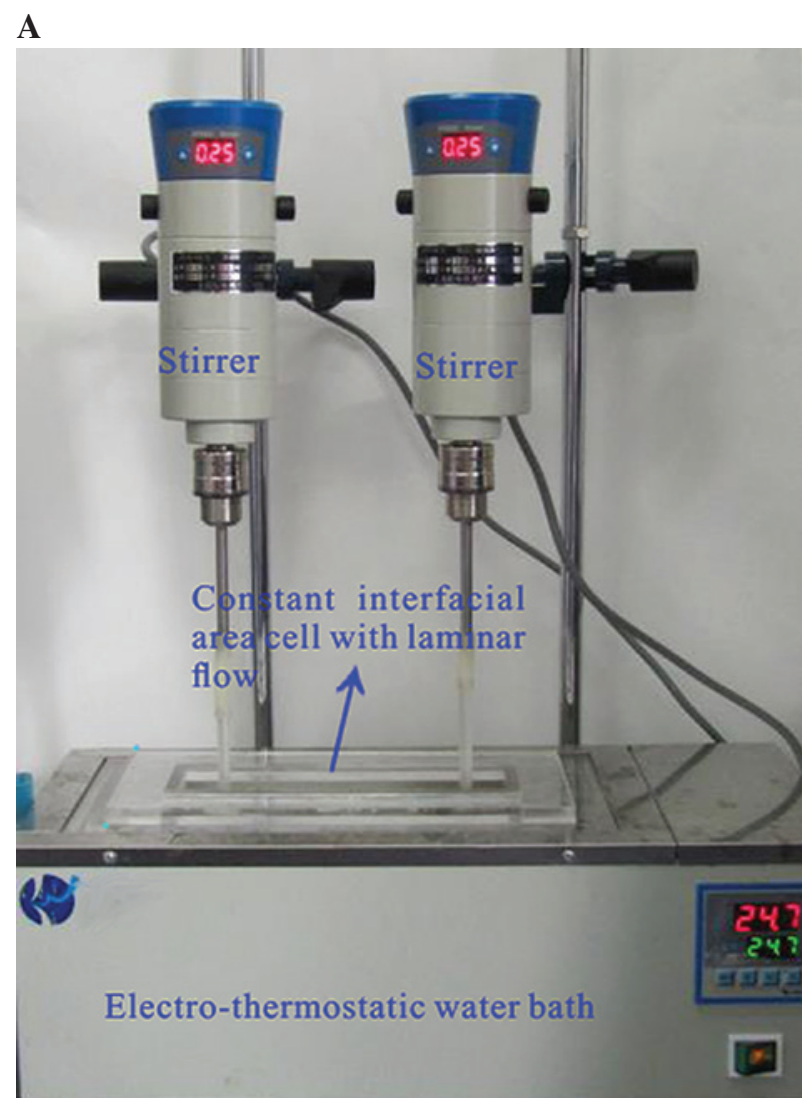

B

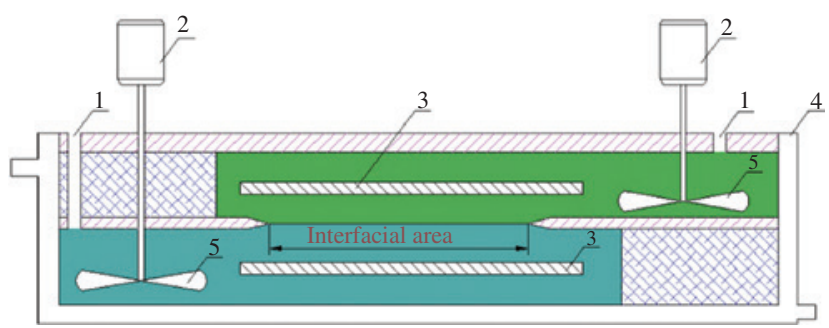

Figure 1: Experimental devices of kinetics $(A)$ and the structure of constant interfacial area cell with laminar flow (B).

1: Sampling aperture; 2: motor; 3: guide plate; 4: electro-thermostatic water bath; and 5: stirring paddle.

[24]. Figure 1 shows the schematic diagram for this constant interfacial area cell. It shows that there are two stirring impellers, one located on one side of the pool and the other at the opposite end of that impeller, the guide plates actions make the fluid reverse the laminar flow keeping the interface stable and at a smooth pace, resulting in there being no flow going towards the interface.

Unless it is otherwise stated, the area of the interface will be $15 \mathrm{~cm}^{2}$. An aliquot of the aqueous phase $(84 \mathrm{ml})$ followed by another aliquot of organic phase are added carefully to the cell chambers using a syringe, and stirring started. Unless otherwise stated, in most experiments, the speed of the stirring in both the phases (in most experiments) will constantly stay at $300 \mathrm{rpm}$. There will be $0.2 \mathrm{ml}$ taken from the aqueous phase, once the stirrer has started, and an interval every $10 \mathrm{~min}$ to take a sample to be analyzed. Unless otherwise stated, there will be a kinetic experiment performed at $298 \mathrm{~K}$. 
Equal volumes of (20 $\mathrm{ml}$ for everyone) the aqueous and organic phases for equilibrium experiments are mixed well by shaking for $30 \mathrm{~min}$ at $298 \pm 1 \mathrm{~K}$.

\subsection{Treatment of rate data}

According to the method used by Danesi and Vandegrift [25], the experimental data were processed. Assuming the mass transfer process is considered as a pseudo-order having a reaction that is nonreversible with respect to cerium(III):

$$
\mathrm{Ce}_{(\mathrm{a})}^{3+} \underset{k_{\mathrm{oa}}}{\stackrel{k_{\mathrm{ao}}}{\rightleftarrows}} \mathrm{Ce}_{(\mathrm{o})}^{3+}
$$

where a and o are aqueous phase and organic phase, respectively. $k_{\mathrm{ao}}$ $\left(\mathrm{cm} \cdot \mathrm{s}^{-1}\right)$ and $k_{\mathrm{oa}}\left(\mathrm{cm} \cdot \mathrm{s}^{-1}\right)$ represent the forward and backward mass transfer coefficients, respectively. $k_{\text {aо }}$ and $k_{\text {оа }}$ have been evaluated with the use of the theoretical treatment that had been developed in the literature.

The rate of change of the number of moles, $n$, with respect to time entering into the organic phase, $\mathrm{d} n / \mathrm{d} t$, is given by Eq. (2) [26]:

$$
\begin{gathered}
\frac{\mathrm{d} n}{\mathrm{~d} t}=Q\left(k_{\mathrm{ao}}\left[\mathrm{Ce}^{3+}\right]_{(\mathrm{a})}-k_{\mathrm{oa}}\left[\mathrm{Ce}^{3+}\right]_{(\mathrm{o})}\right) \\
-\frac{\mathrm{d}\left[\mathrm{Ce}^{3+}\right]_{(\mathrm{o})}}{\mathrm{d} t}=\frac{Q}{V}\left(k_{\mathrm{oa}}\left[\mathrm{Ce}^{3+}\right]_{(\mathrm{o})}-k_{\mathrm{ao}}\left[\mathrm{Ce}^{3+}\right]_{(\mathrm{a})}\right)
\end{gathered}
$$

where $n$ represents the number of moles of Ce(III) in the organic phase; $V$ and $Q$ represent one or the other between the aqueous and the organic phase, as well as the interfacial area cell, respectively.

At the state of being stable, either hand will be equal to zero in Eq. (3). That is:

$$
K_{\mathrm{d}}=\frac{\left[\mathrm{Ce}^{3+}\right]_{(\text {o) }}^{e}}{\left[\mathrm{Ce}^{3+}\right]_{(\text {a) }}^{e}}=\frac{k_{\text {ao }}}{k_{\text {oa }}} .
$$

According to the law of conservation of mass, after logarithm fetch on either side of the equality, it follows that:

$$
\ln \left(1-\frac{\left[\mathrm{Ce}^{3+}\right]_{(\mathrm{o})}}{\left[\mathrm{Ce}^{3+}\right]_{(\mathrm{o})}^{e}}\right)=-\frac{Q}{V}\left(1+K_{\mathrm{d}}\right) k_{\mathrm{oa}} t .
$$

All the slopes in the plots in $\ln \left\{1-\left(\left[\mathrm{Ce}^{3+}\right]_{(\mathrm{o})} /\left[\mathrm{Ce}^{3+}\right]_{(\mathrm{o})}^{e}\right)\right\}$ and against $t$ have been used for the elevation of $k_{\text {оа }}$ and $k_{\mathrm{a} o}$. The value of distribution ratio $K_{\mathrm{d}}$ has been evaluated by determining $\mathrm{Ce}^{3+}$ concentrations that follow the contact of the two phases ( $20 \mathrm{ml}$ each) for a time of $30 \mathrm{~min}$.

\section{Results and discussion}

\subsection{Extraction studies}

From the experiments of extraction kinetics, it is common to identify the extraction rates using criterion by stirring speed. When diffusion process takes control of the

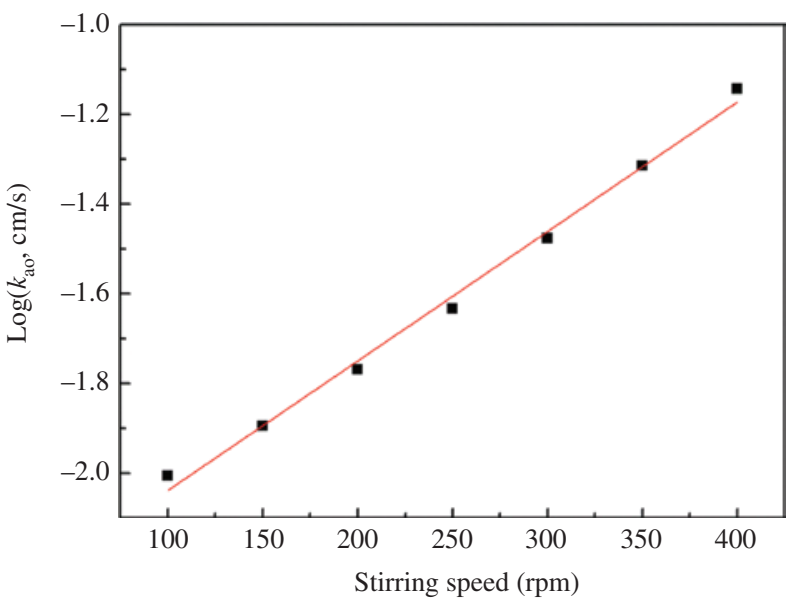

Figure 2: Effect of stirring speed on mass transfer rate. Aqueous phase: $\left[\mathrm{CeCl}_{3}\right]=0.10 \mathrm{~mol} \mathrm{l}^{-1}, \mathrm{pH}=2.00,[\mathrm{HLac}]=0.3 \mathrm{~mol} \mathrm{l}^{-1}$, $\left[\mathrm{H}_{3} \mathrm{Cit}\right]=0.03 \mathrm{~mol} \mathrm{l}^{-1}$; organic phase: $\left[\mathrm{H}_{2} \mathrm{~A}_{2}\right]=0.60 \mathrm{~mol} \mathrm{l}^{-1} ; Q=15 \mathrm{~cm}^{2}$, $T=298 \mathrm{~K}$.

extraction, the rate of extraction is increased with an increased stirring speed, while there is without an effect on the extraction rate governed by chemical reactions [27]. Within this system, the plot (Figure 2) for $\log k_{\mathrm{ao}}$ versus stirring speeds in the range of $100-400 \mathrm{rpm}$ provided an increased trend, thus indicating that extraction rates are dependent on stirring speeds. Meanwhile, the linear relations of stirring speeds and $\log k_{\mathrm{ao}}$ indicate that mass transfer process continues to be influenced by the agitation, even with $400 \mathrm{rpm}$. Therefore, mass transfer process is mostly controlled by diffusion instead of chemical process. The reason may be that chemical reaction rates are quicker than the diffusion rates, thus chemical reaction effect only possesses a small portion [15].

Additionally, if the diffusion-controlled extraction rate has a temperature effect that is more pronounced compared to rates controlled by chemical processes, the activation energy in this case does not generally exceed $20.9 \mathrm{~kJ} \mathrm{~mol}^{-1}[27,28]$. The method of expressing influences on temperature that are most satisfactory with extractions of Ce(III) by D2EHPA in ranges of $20^{\circ} \mathrm{C}-55^{\circ} \mathrm{C}$ is derivable by plotting values of $\log k_{\mathrm{ao}}$ against the absolute temperature $1 / T$ reciprocal. Figure 3 shows results that are represented by a straight line that obeys Arrhenius equation $k_{\mathrm{ao}}=A \cdot e^{-E_{\mathrm{a}}} / R T$, where $R$ is the gas constant, $T$ represents absolute temperature, and $A$ represents frequency factor or pre-exponential factor. The activation energy $E_{\mathrm{a}}$ is calculated using this line as the slope, determined as $13.82 \mathrm{~kJ} \mathrm{~mol}^{-1}$, indicating that the extraction of Ce(III) within the diffusion controlled investigated system, takes place in either the interface or the bulk phase. 


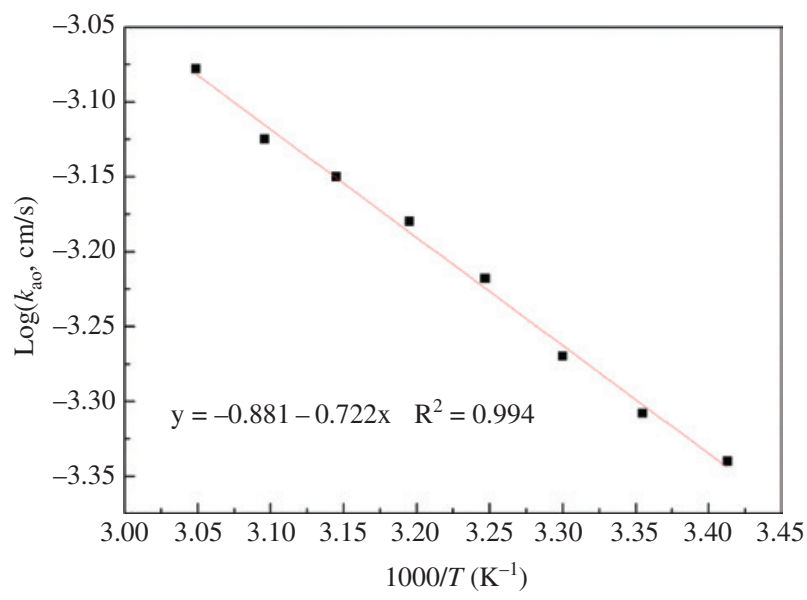

Figure 3: Effect of temperature on mass transfer rate. Aqueous phase: $\left[\mathrm{CeCl}_{3}\right]=0.10 \mathrm{~mol} \mathrm{l}^{-1}, \mathrm{pH}=2.00,[\mathrm{HLac}]=0.3 \mathrm{~mol} \mathrm{l}^{-1}$, $\left[\mathrm{H}_{3} \mathrm{Cit}\right]=0.03 \mathrm{~mol} \mathrm{l}^{-1}$; organic phase: $\left[\mathrm{H}_{2} \mathrm{~A}_{2}\right]=0.60 \mathrm{~mol} \mathrm{l}^{-1} ; Q=15 \mathrm{~cm}^{2}$, stirring speed $=250 \mathrm{rpm}$.

The effects on the interfacial area have been studied by utilizing various interfacial regions within the range of 5.4-15 $\mathrm{cm}^{2}$ while each phase was fixed with a volume of $84 \mathrm{ml}$. Meanwhile, the plots (Figure 4) of various values of $k_{\text {ао }}$ versus certain corresponding interfacial regions $\bar{a}(\bar{a}=$ interfacial area/volume of the phase) have indicated an increase in reaction rates with increases in certain interfacial area, indicating that the extraction rates of $\mathrm{Ce}(\mathrm{III})$ are dependent on variations of interfacial area, and the reaction rates takes place at the interface instead of the bulk phase, which is based on the criterion as follows: if the bulk phase encounters slow chemical reactions, initial rates are independent of certain interfacial areas.

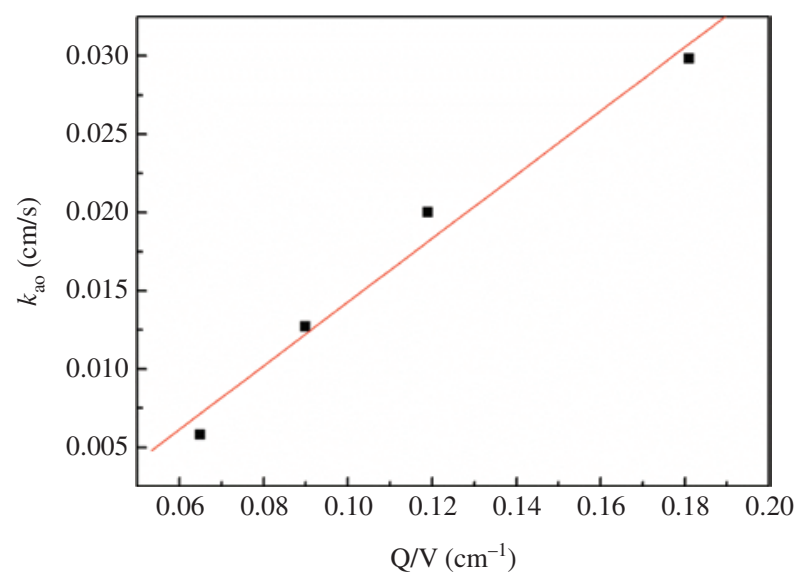

Figure 4: Effect of specific interfacial area on mass transfer rate. Aqueous phase: $\left[\mathrm{CeCl}_{3}\right]=0.10 \mathrm{~mol} \mathrm{l}^{-1}, \mathrm{pH}=2.00,[\mathrm{HLac}]=0.3 \mathrm{~mol} \mathrm{l}^{-1}$, $\left[\mathrm{H}_{3} \mathrm{Cit}\right]=0.03 \mathrm{~mol} \mathrm{l}^{-1}$; organic phase: $\left[\mathrm{H}_{2} \mathrm{~A}_{2}\right]=0.60 \mathrm{~mol} \mathrm{l}^{-1}$; stirring speed $=250 \mathrm{rpm}, T=298 \mathrm{~K}$.
Otherwise, reactions occurring in the interfacial zone indicate direct proportionality between the certain interfacial area and rate.

\subsection{Extraction rate equation}

In addition, our previous investigation indicates that the complexing agents lactic acid and citric acid do not involve the extraction process, on the contrary, they retain in the raffinate. Based on general kinetic equations for formation of metal chelates [22], the rate $R_{\mathrm{f}}$ reaching the extraction equilibrium is expressed as Eq. (6):

$$
R_{\mathrm{f}}=k_{\mathrm{f}}\left[\mathrm{M}^{\mathrm{n}+}\right]\left[\mathrm{L}^{-}\right]^{n}=k_{\mathrm{f}}\left[\mathrm{M}^{\mathrm{n}+}\right]\left[\frac{K_{\mathrm{HL}}(\mathrm{HL}){ }_{(0)}}{\left[\mathrm{H}^{+}\right] \lambda}\right]^{n}
$$

where HL, $k_{f}, \lambda$, and $K_{\mathrm{HL}}$ are acidic extractant, rate constant, partition ratio of extractant between the interface and organic phase, and ionization constant, respectively.

Based on the experimental results, plots for $\ln \left\{1-\left(\left[\mathrm{Ce}^{3+}\right]_{(0)} /\left[\mathrm{Ce}^{3+}\right]_{(0)}^{e}\right)\right\}$ versus time $(t)$ yield straight lines every time, which indicates that first-order reactions are mass transfers being pseudo-first-order reversible reactions.

The effects of $\mathrm{pH}$ values and the concentration of the extractant $\mathrm{H}_{2} \mathrm{~A}_{2}$ on the rate of extraction are investigated separately (Figures 5 and 6). Results indicate that the extraction rate increases as the $\mathrm{pH}$ values and $\mathrm{H}_{2} \mathrm{~A}_{2}$ concentrations increases, with a slope of $0.9800 \approx 1.0$ and a slope of $1.086 \approx 1.0$, respectively. Furthermore, the line slopes show that the extraction of $\mathrm{Ce}(\mathrm{III})$ is inverse

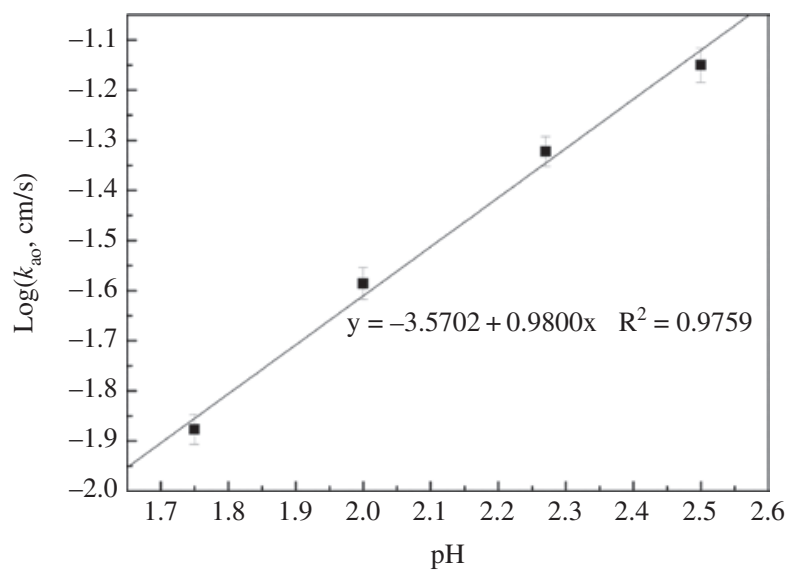

Figure 5: Effect of $\mathrm{pH}$ value in the aqueous phase on extraction rate. Aqueous phase: $\left[\mathrm{CeCl}_{3}\right]=0.10 \mathrm{~mol} \mathrm{l}^{-1}$, $[\mathrm{HLac}]=0.3 \mathrm{~mol} \mathrm{l}^{-1}$, $\left[\mathrm{H}_{3} \mathrm{Cit}\right]=0.03 \mathrm{~mol} \mathrm{l}^{-1}$; organic phase: $\left[\mathrm{H}_{2} \mathrm{~A}_{2}\right]=0.60 \mathrm{~mol} \mathrm{l}^{-1} ; Q=15 \mathrm{~cm}^{2}$, stirring speed $=250 \mathrm{rpm}, T=298 \mathrm{~K}$. 


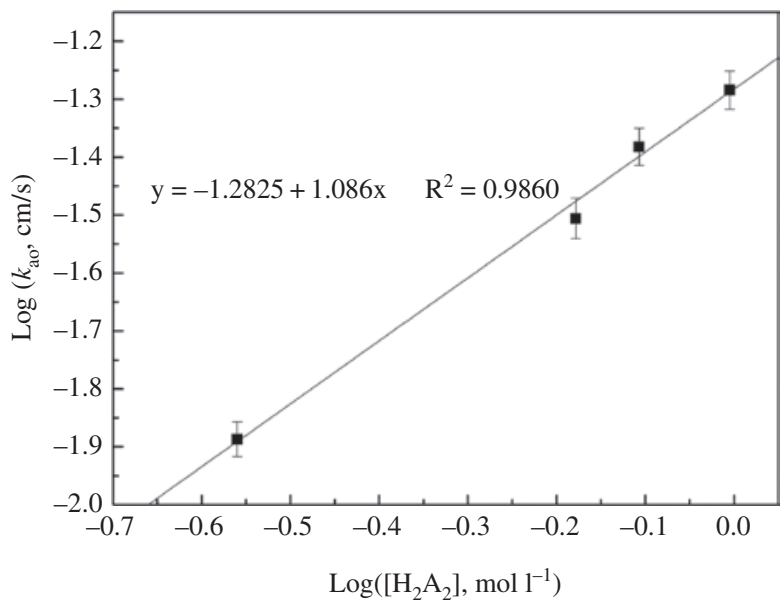

Figure 6: Effect of extractant concentration on extraction rate. $\left[\mathrm{CeCl}_{3}\right]=0.10 \mathrm{~mol} \mathrm{l}^{-1}, \mathrm{pH}=2.00,[\mathrm{HLac}]=0.3 \mathrm{~mol} \mathrm{l}^{-1},\left[\mathrm{H}_{3} \mathrm{Cit}\right]=0.03 \mathrm{~mol} \mathrm{l}^{-1}$, stirring speed $=250 \mathrm{rpm}, Q=15 \mathrm{~cm}^{2}, T=298 \mathrm{~K}$.

first-order dependent on $\left[\mathrm{H}^{+}\right]$as well as first order with respect to $\mathrm{H}_{2} \mathrm{~A}_{2}$ concentration. The rate constant of extraction can be calculated in accordance with the intercepts shown in Figures 5 and $6, k_{\mathrm{f}}=10^{-2.31}$. Based on the experimental results, the rate equation of Ce(III) extraction with $\mathrm{H}_{2} \mathrm{~A}_{2}$ can be written as follows:

$$
R_{\mathrm{f}}=-\frac{\mathrm{d}\left[\mathrm{Ce}^{3+}\right]_{(0)}}{\mathrm{d} t}=10^{-2.31}\left[\mathrm{Ce}^{3+}\right]_{(\mathrm{a})}\left[\mathrm{H}_{2} \mathrm{~A}_{2}\right]_{(\mathrm{o})}\left[\mathrm{H}^{+}\right]_{(\mathrm{a})}^{-1} .
$$

\subsection{Extraction mechanism and kinetic model}

According to the above-mentioned analysis, the stoichiometry of the complex formation reactions between $\mathrm{H}_{2} \mathrm{~A}_{2}$

Table 1: The stepwise metathetical reaction mechanism for the extraction system.

\begin{tabular}{lll}
\hline All rates of each of the steps & Fast or slow & Eq. no \\
\hline $\mathrm{H}_{2} \mathrm{~A}_{2(\mathrm{o})} \stackrel{K_{1}}{\rightleftarrows} \mathrm{H}_{2} \mathrm{~A}_{2(\mathrm{i})} \stackrel{K_{2}}{\rightleftarrows} 2 \mathrm{HA}_{(\mathrm{i})}$ & Fast \\
$\mathrm{Ce}_{(\mathrm{a})}^{3+}+\mathrm{HA}_{(\mathrm{i})} \stackrel{k_{1}}{\rightleftarrows} \mathrm{keA}_{\text {(i) }}^{2+}+\mathrm{H}_{(\mathrm{a})}^{+}$ & Fast \\
$\mathrm{CeA}_{(\mathrm{i})}^{2+}+\mathrm{HA}_{(\mathrm{i})} \stackrel{k_{2}}{\rightleftarrows} \mathrm{keA}_{-2}^{+} \mathrm{Ce}_{2(\mathrm{i})}^{+}+\mathrm{H}_{(\mathrm{a})}^{+}$ & Slow \\
$\mathrm{CeA}_{2(\mathrm{i})}^{+}+\mathrm{HA}_{(\mathrm{i})} \stackrel{K_{\mathrm{e} 1}}{\rightleftarrows} \mathrm{CeA}_{3(\mathrm{i})}+\mathrm{H}_{(\mathrm{a})}^{+}$ & Fast \\
$\mathrm{CeA}_{3(\mathrm{i})}+\frac{3}{2} \mathrm{H}_{2} \mathrm{~A}_{2(0)} \stackrel{K_{\mathrm{e} 2}}{\rightleftarrows} \mathrm{CeA}_{3} \cdot 3 \mathrm{HA}_{(0)}$ & Fast
\end{tabular}

Where: subscripts $\mathrm{a}, \mathrm{o}$, and $\mathrm{i}$ are the aqueous, organic, and interface phases, respectively; $k_{1}, k_{2}, k_{-1}$, and $k_{-2}$ are forward and reverse rate constants for the reactions. $K_{1}$ is the dimeric extractant partition ratio between the interface and organic phase. $K_{2}$ is the dissociation constant. $K_{\mathrm{e} 1}$ and $K_{\mathrm{e} 2}$ are equilibrium constants. and Ce shows the following formula of $\mathrm{CeA}_{3} \cdot 3 \mathrm{HA}_{(0)}$. Also, the complex agents $\mathrm{H}_{3} \mathrm{Cit}$ and HLac are not extracted in the organic phase in the extraction process, which has been certified in the prior studies [18].

The stepwise metathetical reaction mechanism has been applied for analyzing the rate controlling phase (Table 1). Therefore, the following equations can be used to represent the process of extraction.

According to Eq. (8), the following equation can be obtained:

$$
\begin{aligned}
& K_{1}=\frac{\left[\mathrm{H}_{2} \mathrm{~A}_{2(\mathrm{i})}\right]}{\left[\mathrm{H}_{2} \mathrm{~A}_{2(\mathrm{o})}\right]} K_{2}=\frac{\left[\mathrm{HA}_{(\mathrm{i})}\right]^{2}}{\left[\mathrm{H}_{2} \mathrm{~A}_{2(\mathrm{i})}\right]} \\
& {\left[\mathrm{HA}_{(\mathrm{i})}\right]^{2}=K_{2}\left[\mathrm{H}_{2} \mathrm{~A}_{2(\mathrm{i})}\right]=K_{2} K_{1}\left[\mathrm{H}_{2} \mathrm{~A}_{2(\mathrm{o})}\right] .}
\end{aligned}
$$

If the instantaneous state is assumed, while the $k_{-2}$ rate constant is ignored, the concentration of $\left[\mathrm{CeA}_{(\mathrm{i})}^{2+}\right]$ can be calculated from Eq. (14):

$$
\frac{\mathrm{d}\left[\mathrm{CeA}_{(\mathrm{i})}^{2+}\right]}{\mathrm{d} t}=k_{1}\left[\mathrm{Ce}_{(\mathrm{a})}^{3+}\right]\left[\mathrm{HA}_{(\mathrm{i})}\right]-k_{-1}\left[\mathrm{CeA}_{(\mathrm{i})}^{2+}\right]\left[\mathrm{H}_{(\mathrm{a})}^{+}\right]-k_{2}\left[\mathrm{CeA}_{(\mathrm{i})}^{2+}\right]\left[\mathrm{HA}_{(\mathrm{i})}\right] .
$$

By assuming interfacial is a steady state that is instantaneous, i.e. $\frac{\mathrm{d}\left[\mathrm{CeA}_{(\mathrm{i})}^{2+}\right]}{\mathrm{d} t}=0$.

It follows that:

$$
\left[\mathrm{CeA}_{(\mathrm{i})}^{2+}\right]=\frac{k_{1}\left[\mathrm{Ce}_{(\mathrm{a})}^{3+}\right]\left[\mathrm{HA}_{(\mathrm{i})}\right]}{k_{-1}\left[\mathrm{H}_{(\mathrm{a})}^{+}\right]+k_{2}\left[\mathrm{HA}_{(\mathrm{i})}\right]} .
$$

By assuming that Eq. (10) is the rate-controlling step, the following rate law is obtained:

$$
R_{\mathrm{f}}=k_{2}\left[\mathrm{CeA}_{(\mathrm{i})}^{2+}\right]\left[\mathrm{HA}_{(\mathrm{i})}\right]=\frac{k_{1} k_{2} K_{1} K_{2}\left[\mathrm{Ce}_{(\mathrm{a})}^{3+}\right]\left[\mathrm{H}_{2} \mathrm{~A}_{2(0)}\right]}{k_{-1}\left[\mathrm{H}_{(\mathrm{a})}^{+}\right]+k_{2}\left[\mathrm{HA}_{(\mathrm{i})}\right]} .
$$

By assuming that $\mathrm{Ce}^{3+}$ rate transfers from aqueous to the organic phase, it could be faster than the reverse rate, $k_{-1}\left[\mathrm{H}^{+}\right]>>k_{2}\left[\mathrm{HA}_{(\mathrm{i})}\right]$, therefore, the extraction rate equation can be written as:

$$
R_{\mathrm{f}}=k_{2}\left[\mathrm{CeA}_{(\mathrm{i})}^{2+}\right]\left[\mathrm{HA}_{(\mathrm{i})}\right]=k_{\mathrm{f}}\left[\mathrm{Ce}_{(\mathrm{a})}^{3+}\right]\left[\mathrm{H}_{2} \mathrm{~A}_{2(0)}\right]\left[\mathrm{H}_{(\mathrm{a})}^{+}\right]^{-1},
$$

where $k_{1} k_{2} K_{1} K_{2} / k_{-1}=k_{\mathrm{f}^{*}}$

The above mechanism is in accordance with Eq. (7) that is obtained by experimental results. The identity of the reaction zone and extraction regime confirms that liquid-liquid interface reaction zones and diffusion control regime occur under these conditions. Thus, the 


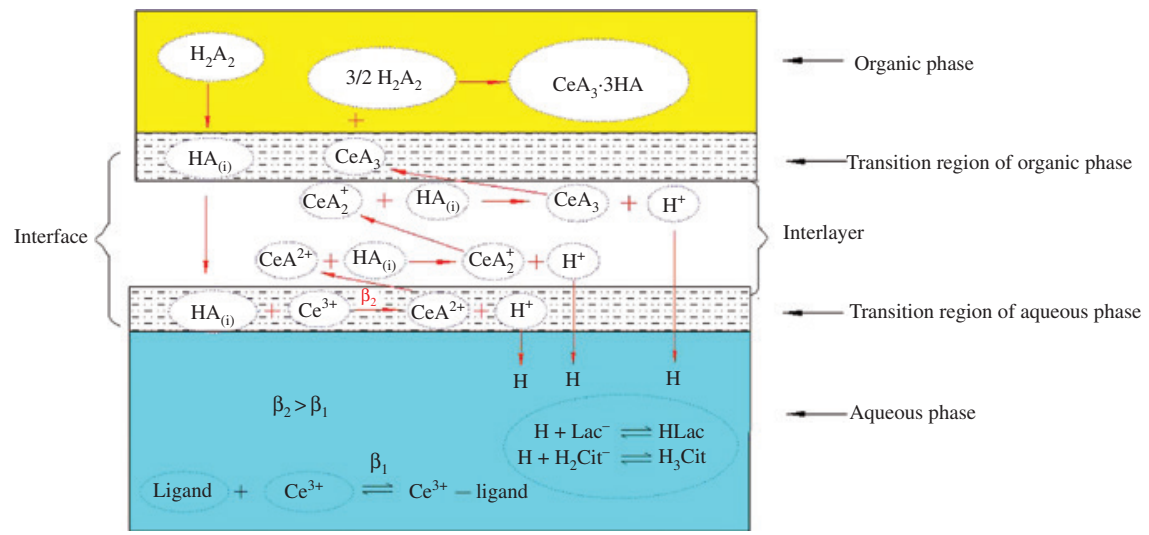

Figure 7: Model of the extraction interface.

rate-controlling phase takes place in the liquid-liquid interface.

The extraction process of $\mathrm{Ce}^{3+}$ results in diffuses from the bulk of aqueous to reaction zones that are located within the layer of aqueous diffusion that adheres to the organic/aqueous interface. Additionally, the dimeric D2EHPA extractant $\left(\mathrm{H}_{2} \mathrm{~A}_{2}\right)$ diffuses from organic to interface reaction zones while ionizing into monomeric acid. Then, $\mathrm{CeA}_{(\mathrm{i})}^{2+}$ species are formed firstly at the interface, and the $\mathrm{CeA}_{3(\mathrm{i})}$ species are formed last, step by step. Meanwhile, three hydrogen ions are released. The $\mathrm{CeA}_{3(\mathrm{i})}$ species is extracted using $\mathrm{H}_{2} \mathrm{~A}_{2}$ within the organic phase from the last $\mathrm{CeA}_{3} \cdot 3 \mathrm{HA}_{(0)}$ complex, meanwhile, the hydrogen ions are released and combined with $\mathrm{H}_{2} \mathrm{Cit}^{-}$and $\mathrm{Lac}^{-}$ for forming $\mathrm{HLac}$ and $\mathrm{H}_{3}$ Cit for buffering effects of higher acidy changes on extraction.

According to the expression above, Figure 7 shows the interface geometry model.

\section{Conclusions}

The $\mathrm{Ce}^{3+}$ extraction kinetics from chloride solution with two complex agents $\mathrm{H}_{3} \mathrm{Cit}$ and $\mathrm{HLac}$ are performed. It was discovered as following:

(1) Kinetic investigations show that controlling reactions of $\mathrm{Ce}^{3+}$ extraction by D2EHPA in kerosene with a chloride medium occurs with a controlled diffusion at the interface level instead of in bulk phase, under conditions of stirring speed ranging from 100 to $400 \mathrm{rpm}$, temperature ranging from $20^{\circ} \mathrm{C}$ to $55^{\circ} \mathrm{C}$ and interfacial regions ranging from 5.4 to $15 \mathrm{~cm}^{2}$.

(2) According to correlated experimental data as the concentration function of $\mathrm{pH}$ value and $\mathrm{H}_{2} \mathrm{~A}_{2}$ extractant, theequation rateofCe ${ }^{3+}$ extraction using $\mathrm{H}_{2} \mathrm{~A}_{2}$ isobtained as $R_{\mathrm{f}}=-\frac{\mathrm{d}\left[\mathrm{Ce}^{3+}\right]_{(0)}}{\mathrm{d} t}=10^{-2.31}\left[\mathrm{Ce}^{3+}\right]_{(\mathrm{a})}\left[\mathrm{H}_{2} \mathrm{~A}_{2}\right]_{(0)}\left[\mathrm{H}^{+}\right]_{(\mathrm{a})}^{-1}$.

(3) Predictions collected from interfacial reaction models provided the rate-determining step along with the proposed interfacial consecutive reaction model.

Acknowledgments: Financial aid from the following programs is gratefully acknowledged: the National Natural Science Foundation of China (51504116), and the Kunming University of Science and Technology Personnel Training Fund (KKSY201452088).

\section{References}

[1] Wang Q, Yue M, Zhong Q, Cui MS, Huang XW, Hou YK, Wang L, Yang YX, Long ZQ, Feng ZY. J. Rare Earths 2016, 34, 695-703.

[2] Wu WY, Li SW, Chen J, Yang GS, Tu GF. J. Rare Earths 2007, 25, 125-128.

[3] Tao F, Yang SS, Yang P, Shi ZN, Zhou RX. J. Rare Earths 2016, 34, 381-389.

[4] Yahi N, Menad S, Rodriguez Ramos I. Green Process. Synth. 2015, 4, 479-486.

[5] Cen P, Wu WY, Bian X. Green Process. Synth. 2016, 5, 427-434.

[6] Cheng DH, Chen XW, Shu Y, Wang JH. Talanta 2008, 75, 1270-1278.

[7] James EQ, Karin HS, Geoffrey WS. Hydrometallurgy 2017, 169, 621-628.

[8] Lu YC, Wei HQ, Zhang ZF, Li YL, Wu GL, Liao WP. Hydrometallurgy 2016, 163, 192-197.

[9] Ahmed AA, Susumu N, Fumio K, Katsuroku T. Sep. Purif. Technol. 2002, 26, 265-272.

[10] Sun XB, Meng SL, Li DQ. J. Chem. Technol. Biotechnol. 2006, $81,755-760$.

[11] Zhang ZF, Li HF, Guo FQ, Meng SL, Li DQ. Sep. Purif. Technol. 2008, 63, 348-352. 
[12] Yin SH, Li SW, Zhang B, Peng JH, Zhang LB. Hydrometallurgy 2016, 161, 160-165.

[13] Yin SH, Li SW, Zhang B, Peng JH, Zhang LB. Chem. Eng. Res. Des. 2015, 104, 92-97.

[14] Liu JJ, Wang YL, Li DQ. J. Chem. Technol. Biotechnol. 2007, 82, 949-955.

[15] Wang XL, Meng SL, Li DQ. Sep. Purif. Technol. 2010, 71, 50-55.

[16] He WW, Liao WP, Wang WW, Li DQ, Niu CJ. J. Chem. Technol. Biotechnol. 2008, 83, 1314-1320.

[17] Yin SH, Wu WY, Bian X, Zhang FY. Hydrometallurgy 2013, 131, 133-137.

[18] Yin SH, Wu WY, Bian X, Luo Y, Zhang FY. Ind. Eng. Chem. Res. 2013, 52, 8558-8564.

[19] Yin SH, Li SW, Wu WY, Bian X, Peng JH, Zhang LB. RSC Adv. 2014, 4, 59997-60001.
[20] Xie F, Dreisinger D, Doyle F. Miner. Process. Extr. Metall. Rev. 2013, 34, 387-411.

[21] Konyratbekova SS, Baikonurova A, Akcil A. Extr. Metall. Rev. 2015, 36, 198-212.

[22] Szymanowski J, Cote G, Blondet I, Bouvier C, Bauer D, Sabot JL. Hydrometallurgy 1997, 44, 163-178.

[23] Shen LS. Chemical Analysis Handbook, Water Resources and Electric Power Press: Beijing, 1991.

[24] Zheng Z, Li DQ. In Value Adding Through Solvent Extraction (Proceedings ISEC' 96), Shallcross, DC, Paimin, R, Prvcic, LM, Eds., University of Melbourne: Australia, 1996, Vol. 1, pp. 171-176.

[25] Danesi PR, Vandegrift GF. J. Phys. Chem. 1981, 85, 3646-3651.

[26] Vandegrift GF, Horwitz EP. J. Inorg. Nucl. Chem. 1977, 39, 1425-1432.

[27] Danesi PR, Chiarizia R. Anal. Chem. 1980, 10, 1-126.

[28] Yu JF, Ji C. Chem. J. Chin. Univ. 1992, 13, 224-226. 